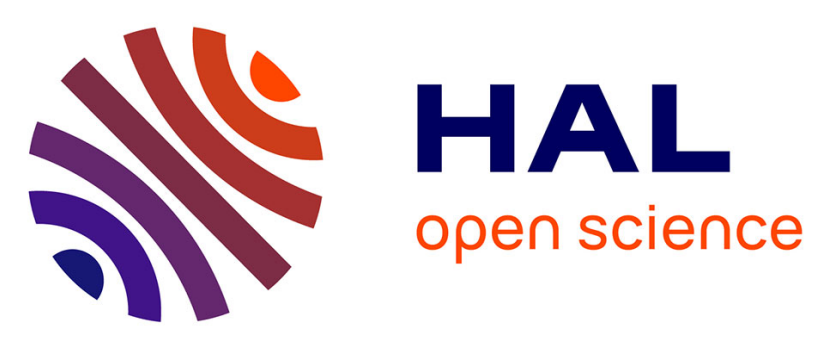

\title{
Functionalized SERS substrate based on silicon nan-owires for rapid detection of prostate specific antigen
}

\author{
Awatef Ouhibi, Amal Raouafi, Nathalie Lorrain, Mohammed Guendouz, \\ Noureddine Raouafi, Adel Moadhen
}

\section{To cite this version:}

Awatef Ouhibi, Amal Raouafi, Nathalie Lorrain, Mohammed Guendouz, Noureddine Raouafi, et al.. Functionalized SERS substrate based on silicon nan-owires for rapid detection of prostate specific antigen. Applied Spectroscopy, 2021, 330, pp.129352. 10.1016/j.snb.2020.129352 . hal-03095933v2

\section{HAL Id: hal-03095933 \\ https://hal.science/hal-03095933v2}

Submitted on 22 Feb 2021

HAL is a multi-disciplinary open access archive for the deposit and dissemination of scientific research documents, whether they are published or not. The documents may come from teaching and research institutions in France or abroad, or from public or private research centers.
L'archive ouverte pluridisciplinaire HAL, est destinée au dépôt et à la diffusion de documents scientifiques de niveau recherche, publiés ou non, émanant des établissements d'enseignement et de recherche français ou étrangers, des laboratoires publics ou privés. 


\title{
Functionalized SERS substrate based on silicon nanowires for rapid detection of prostate specific antigen
}

\author{
Awatef Ouhibi ${ }^{1}$, Amal Raouafi ${ }^{2}$, Nathalie Lorrain ${ }^{3}$, Mohammed Guendouz ${ }^{3}$, Noureddine \\ Raouafi $^{2^{* *}}$ and Adel Moadhen ${ }^{1 * *}$
}

${ }^{1}$ Université de Tunis El Manar, Faculté des Sciences de Tunis, Laboratoire de Nanomatériaux Nanotechnologie et Energie (LR19ES23), 2092, Tunis El Manar, Tunisie

${ }^{2}$ Université de Tunis El Manar, Faculté des Sciences de Tunis, Laboratoire de Chimie Analytique et Electrochimie (LR99ES15), Sensors and Biosensors group, 2092, Tunis El Manar, Tunisie

${ }^{3}$ UMR FOTON, CNRS, Université de Rennes 1, Enssat, BP 80518, 6 rue Kerampont, F22305, Lannion, France

Corresponding authors:* noureddine.raouafi@fst.utm.tn

** adel.moadhen@istmt.utm.tn

\begin{abstract}
Owing to its high sensitivity, surface-enhanced Raman spectroscopy (SERS) is largely used in biosensing as an efficient optical technique. In this work, we report the elaboration of a novel SERS substrate based aptasensor for ultra-sensitive and selective detection of prostate specific antigen (PSA). The SERS substrate is based on silicon nanowires (SiNWs) as transducer surface coated by silver nanoparticules (AgNPs). The silver nanoparticles have two purposes : a) aptamer immobilization via thiol chemistry and b) Raman signal enhancement. The presence of PSA induces the appearance of amide vibration modes only if the aptamer is present on the surface of SiNWs. The platform is highly sensitive, selective and specific to PSA in a wide range of concentrations from 0.1 to $20 \mu \mathrm{g} . \mathrm{L}^{-1}$ with a detection limit of $0.1 \mu \mathrm{g} . \mathrm{L}^{-1}$, which encompasses the blood serum range of healthy subjects and ill patients. This optical biosensor shows a great stability and it is successfully validated in human blood serum samples showing very good results.
\end{abstract}

Keywords

SERS; SiNWs; AgNPs; PSA; Aptasensor 


\section{Introduction}

Cancer has been ranked on top as one of the major challenges for human survival due to its great threat to health worldwide. Prostate cancer is the most common cancer related to men over 50 years. It has a high mortality rate when it is diagnosticated in advanced stages [1-3]. It is recommended that subjects with a family history with this cancer have to check themselves from the age of 45. Early individual diagnosis is urgently needed to reduce mortality, to increase the life expectancy (at least 10 years) and to improve the treatment outcome [4]. Early diagnosis of prostate cancer is related to prostate specific antigen (PSA) that is regarded as a gold standard biomarker. PSA is a 34-KDa single-chain glycoprotein secreted by the prostate gland [3]. The normal level of this protein in the serum is less than $4 \mu \mathrm{g} . \mathrm{L}^{-1}$. A level above this value is often suspected when malformation or tumors appear in the prostate gland [5]. To date, several analytical assays such as enzyme-linked immunosorbent assay [6, 7], chemiluminescence immunoassay [8], immunosensors [9], radioimmunoassay [10] and luminescent immunoassay are commonly used to determine PSA levels in blood serum [11].

On another hand, SERS is also a powerful analytical tool that can be used for detection of proteins, DNA and small molecules [12]. Compared with fluorescence and electrochemistry based methods, SERS can provide steady and sharp fingerprint spectra in complex samples with a low background interference [13] thanks to its inherent characteristics such as short analysis time, high sensitivity, low detection limit, small sample volume requirement and its non-destructive nature $[14,15]$.

Several developed strategies are based on antibody/antigen biorecognition. However, antibodies are subject to degradation and are bulky biomolecules (160 KDa) [16]. In addition, in vivo preparation of antibodies is expensive, time consuming and difficult to achieve [17]. For these reasons, the choice of antibody-based biosensors is being replaced by aptamer-based sensors. In fact, the rapid emergence of aptamers as alternative capture molecules has opened the way to new diagnostic platforms. Aptamers are single-stranded DNA or RNA oligonucleotides selected by systematic evolution of ligands by exponential enrichment (SELEX) [18]. Their interest lies in their high selectivity, specificity, binding affinity and stability, which allow them differentiating isoforms and splicing variants of a protein and to form distinct secondary structures capable of binding to RNA, DNA or target proteins. It is also easy to chemically modify them by many functional groups, such as amine biotin and thiol groups. In addition, aptamers could be denatured and renatured several times [19]. In the last decades, a lot of 
work has been done to build new aptamer-based methods for PSA detection such as electrochemical [20, 21], fluorescence [22] and SERS techniques [23].

Another important parameter in biosensing is the transducer material. Silicon nanowires, which are a one-dimensional nanomaterial with a large specific surface area [24], are one of the most used nanomaterial in SERS-based biosensors. Taking advantage of the characteristic surface plasmon resonance of silver nanoparticles [25], which act as signal enhancing substrates, the combination of these two materials has been widely used as a transducer material to develop SERS sensors [26]. In view of the above, we report here the development of a SERS aptasensor for selective, sensitive and inexpensive prostate specific antigen detection. The SERS substrate was functionalized first by a very dense layer of self-assembled hexanethiol, then partially exchanged by the self-assembled thiol-terminated DNA aptamer for target recognition. The platform serves to sensitively and selectively detect PSA in spiked PBS solutions. Upon optimization of the detection parameters, the device was successfully applied to detect PSA in spiked human serum samples.

\section{Materials and methods}

\subsection{Reagents}

Silver nitrate, hydrofluoric acid (40\%), hydrogen peroxide (34\%), nitric acid (70\%), sulfuric acid $(97 \%)$ and hexanethiol $(\mathrm{MCH})$ were purchased from Sigma-Aldrich (www.sigmaaldrich.com). All these solutions were prepared using ultrapure water produced by a Millipore system. Anti-PSA specific DNA aptamer modified with thiol group at the 5'end (5' $\mathrm{C}_{6} \mathrm{H}_{13}$ S-TTTTTAATTAAAGCTCGCCATCAAATAGCTTT-3') was acquired from Biomers (Germany, www.biomers.net). PSA molecules were purchased from MerckMillipore (Massachusetts, USA, www.merckmillipore.com).

\subsection{Apparatuses}

SERS measurements were performed at room temperature (RT) on a Micro Raman HORIBA system (LabRAM HR800). A helium-Neon laser excitation $632.8 \mathrm{~nm}$ was used and has a power of about $5 \mathrm{~mW}$ at the sample surface.

The morphological properties and the composition analysis of the as prepared samples were assessed by scanning electron microscopy (SEM) using respectively a JEOL JSM 7100F thermal field emission electron gun microscope and a HITACHI FLEX SEM II microscope equiped with an Energy Dispersive of X ray (EDX) detector. The XRD spectra were recorded using a Bruker D8 diffractometer operating with $\mathrm{Cu}$ Ka1/Ka2 radiation. The absorbance spec- 
tra were measured using UV-Vis-NIR spectrophotometer (Perkin-Elmer Lambda 950) at RT in the wavelength range from 400 to $500 \mathrm{~nm}$.

\subsection{Bioplatform assembly and operation}

The stepwise development of our label-free SERS aptasensing platform for PSA is illustrated in Fig. 1. Briefly, SiNWs were prepared by metal-assisted chemical etching (MACE) from lightly N-doped Si (100) wafers [27]. Then, AgNPs were deposited on SiNWs nanostructure through the electroless deposition technique by the reduction of $\mathrm{Ag}^{+}$[28]. Then, SiNWs were immersed in an aqueous solution of $\mathrm{HF}$ and $\mathrm{AgNO}_{3}$ under the optimal conditions found in our previous study devoted for rhodamine 6G detection [26]. The AgNPs/SiNWs were further functionalized with a densely packed self-assembled layer of hexanethiol, to avoid nonspecific binding of the analyte on the surface, by incubating the SERS substrate in $10^{-3} \mathrm{M}$ of MCH $[29,30]$. Since the arrangement of the thiolated DNA on sensor surfaces has a deep impact on molecular recognition [31], the thiol-terminated DNA aptamer (anti-PSA) was tethered to the surface by exchanging with already adsorbed thiols through immersing $\mathrm{MCH} / \mathrm{AgNPs} / \mathrm{SiNWs}$ substrate $\left(1 \times 1 \mathrm{~cm}^{2}\right.$ wafer $)$ in $2 \mathrm{~mL}$ of $1 \mu \mathrm{M}$ of anti-PSA aptamer dissolved in PBS for 4, 8, 12 and 16h at RT. The wafer was removed from the solution, washed twice with PBS solution and twice with deionized water then dried under a gentle $\mathrm{N}_{2}$ flux.

In the last step, the aptasensor (anti-PSA/MCH/AgNPs/SiNWs) was incubated for $30 \mathrm{~min}$ with different concentrations of PSA dissolved in phosphate buffered saline solution at $\mathrm{pH} 7.4$ [32]. Finally, the prepared substrates were thoroughly washed and dried before Raman measurement.

\section{Figure 1}

\section{Results and discussion}

\subsection{Morphological characterization}

The SEM cross section image of SiNWs shows a one-dimensional structure with a thickness of about $15 \mu \mathrm{m}$ as it is displayed in Fig. 2A. The SEM surface image of AgNPs/SiNWs presented in Fig. 2B shows that the AgNPs have almost spherical shapes with a relatively uniform size (mean diameter of $100 \mathrm{~nm}$ ) and they are uniformly distributed over the surface of the SiNWs. The EDX analysis have been performed on the SEM cross-sectional of the SiNWs before and after the deposition of the AgNPs. Fig. 2C displays the EDX spectrum of AgNPs / SiNWs from the surface to $1.6 \mu \mathrm{m}$, this spectrum shows that the mass percentage of silver in 
this area is of the order of $2 \%$. This percentage decreases with depth until it cancels at a depth of $4.5 \mu \mathrm{m}$ as it can be seen in Fig. 2D.

The UV-Vis absorbance spectra of SiNWs and AgNPs/SiNWs show absorbance values above $96 \%$ over a wavelength range from 400 to $500 \mathrm{~nm}$. The AgNPs/SiNWs spectrum is characterized by the presence of a weak plasmon band of AgNPs at about $440 \mathrm{~nm}$ [33-34]. This weak band is most likely due to the low density of silver nanoparticles on the surface of SiNWs (Fig. 2E).

The XRD spectrum of SiNWs shows the existence of some silicon diffraction peaks at $2 \theta=$ $32^{\circ}$ and $61.5^{\circ}$ which are related to the crystallographic planes of silicon [200] and [004], respectively. The XRD spectrum of AgNPs/SiNWs shows, in addition to the peaks of SiNWs, the existence of other peaks at $2 \theta=37.9^{\circ}, 44.3^{\circ}$ and $56.2^{\circ}$ which are respectively attributed to [111], [200] and [211] planes of the faceted cubic silver crystals [35, 36] as it can be seen in Fig. 2F. This spectrum also confirms the presence of the silver nanoparticles on the SiNWs surface.

\section{Figure 2}

\subsection{Optimization of the aptamer incubation time}

The surface modification of MCH/AgNPs/SiNWs by anti-PSA aptamer was evaluated by Raman. As displayed in Fig. 3A and Fig. 3B, which show the SERS spectra of MCH/AgNPs/SiNWs and anti-PSA/MCH/AgNPs/SiNWs for different incubation times $(4,8$, 12 and 16 hours) of the substrate in aptamer, dissolved at $1 \mu \mathrm{M}$ in PBS, for both frequency ranges of 550-1700 $\mathrm{cm}^{-1}$ and $2800-3100 \mathrm{~cm}^{-1}$, respectively. The control Raman spectrum of $\mathrm{MCH} / \mathrm{AgNPs} / \mathrm{SiNWs}$ highlights the vibration modes of the adsorbed hexanethiol. The main vibration modes are located at 632 and $706 \mathrm{~cm}^{-1}$ and attributable to $v(\mathrm{C}-\mathrm{S})_{\mathrm{G}}$ and $\mathrm{v}(\mathrm{C}-\mathrm{S})_{\mathrm{T}}$, respectively. Additionnally, the modes at 890,1080, 2867, 2931 and $3060 \mathrm{~cm}^{-1}$ are attributed to $\rho\left(\mathrm{CH}_{3}\right), v(\mathrm{C}-\mathrm{C})_{\mathrm{G}}, v\left(\mathrm{CH}_{3}\right), v\left(\mathrm{CH}_{2}\right)_{\mathrm{s}}$ and $v\left(\mathrm{CH}_{2}\right)_{\text {as }}$, respectively [37-39].

For longer incubation times, several changes are visible. As it is shown in Fig. 3A and Fig. 3B, MCH modes undergo a decrease in their scattered intensities, such as the modes at 632, 706 and $1080 \mathrm{~cm}^{-1}$, whereas some others experience an increase such as at 2867 and $2931 \mathrm{~cm}^{-}$ ${ }^{1}$. The decreased vibrations are the eigen modes of $\mathrm{MCH}$ while the other ones $\left(\mathrm{CH}_{2}\right)$ exist also in aptamer and the increase of their intensities indicates that the amount of $\mathrm{CH}_{2}$ groups on the surface is becoming higher. Fig. 3A shows also the apparition of time-dependent new vibration modes such as the modes at 960, 1107 and $1449 \mathrm{~cm}^{-1}$, which are the eigen modes at- 
tributed to $\mathrm{NH}_{2}$ group of adenine, $\mathrm{PO}_{2}$ stretching and deoxyribose, respectively [40-43]. The intensity decrease of $\mathrm{MCH}$ vibration modes and concomitant intensity increase of aptamer vibrations can be explained by the exchanging of a densely packed self-assembled layer of hexanethiol by a thiolated anti-PSA aptamer.

\subsection{Optimization of the SERS response to the presence of PSA}

The PSA signature is closely dependent on the amount of aptamer present in the surface of the SERS substrate. So, the effect of varying the incubation time (4h, $8 \mathrm{~h}, 12 \mathrm{~h}$ and $16 \mathrm{~h}$ ) of $\mathrm{MCH} / \mathrm{AgNPs} / \mathrm{SiNWs}$ in aptamer solutions was studied to determine the fittest one. Fig. 3C shows the SERS spectra of PSA $\left(1 \mu \mathrm{g} . \mathrm{L}^{-1}\right) /$ anti-PSA/MCH/AgNPs/SiNWs substrate prepared at different incubation times in aptamer solutions. At relatively short incubation times in aptamer (4h and 8h), the PSA/ anti-PSA/MCH/AgNPs/SiNWs spectra do not show clearly the Raman vibration modes of PSA. For times longer than 12 hours, these spectra show clearly the PSA signature, through the Raman vibration modes of amides. For instance, the newly visible peaks are located at $1650,1550,1300 \mathrm{~cm}^{-1}$ are respectively assigned to amides I, II and III [44-46]. The intensities of these modes increase with time from $4 \mathrm{~h}$ to $16 \mathrm{~h}$. The incubation time of $\mathrm{MCH} / \mathrm{AgNPs} / \mathrm{SiNW}$ in aptamer was chosen $16 \mathrm{~h}$ to carry out the work. Times superior to $16 \mathrm{~h}$ were not assayed since the latter gives satisfactory results and is a good comprise between overall experiment duration and sensitive detection of the target.

\subsection{Sensing of PSA}

The Fig. 3D presents the SERS spectra of the aptasensing platform before and after the incubation of anti-PSA(16h)/MCH/AgNPs/SiNWs substrate in PSA solutions ranging from 0.1 to $20 \mu \mathrm{g} . \mathrm{L}^{-1}$. As it can be seen in this figure, the addition of PSA solution induces the appearance of new peaks, such as the vibration modes of amide III at $1300 \mathrm{~cm}^{-1}$ and amide II at 1550 $\mathrm{cm}^{-1}$. The intensity of these modes increases concomitantly with the increase of PSA concentration. This increase indicates that the PSA amounts on the surface is becoming larger. Accordingly, the intensities of the Raman vibration mode at $1550 \mathrm{~cm}^{-1}$ were used to plot the calibration curve representing the Raman intensity $v s$. the target concentration in solution. The aptasensor is able to detect PSA in a wide linear range of concentration ranging from 0.1 to 20 $\mu \mathrm{g} . \mathrm{L}^{-1}$. The linear regression equation, shown in Figure Fig. 3E, is:

$$
\text { Raman intensity (a.u) }=26[\mathrm{PSA}]\left(\mu \mathrm{g} \cdot \mathrm{L}^{-1}\right)+300
$$

The correlation coefficient of the linear curve is $\mathrm{R}^{2}=0.992$ and the obtained limit of detection (LOD) is $0.1 \mu \mathrm{g} . \mathrm{L}^{-1}$. This parameter was calculated according to the $3 S_{\mathrm{b}} / m$ criterion, where $m$ 
is the slope of the calibration curve and $S_{\mathrm{b}}$ was estimated as the standard deviation of three different measurements recorded for the lowest analyte concentration measured.

\section{Figure 3}

The reported label-free aptasensor for PSA detection shows an excellent analytical behavior compared to previously reported works as displayed in Table 1. For instance, it is outperformed by the electrochemical biosensors reported in [32], [37] and [50] in terms of LOD and dynamic ranges but this biosensor is easier to build and have a higher selfe-life (up to 2 months). Moreover, it performanced better than those using fluorescence and SERS spectroscopies reported in references [51] and [52] using polymer quantum dots or two antibodies, respectively. Overall, this device displays satisfactory performances in terms of linear range and limit of detection, which remains sufficient to conveniently detect the analyte in human blood serum with moderate diluations of the serum samples. Moreover, the use of an antiPSA aptamer instead of antibodies insure more stability and a low-cost device. The SERSbased techniques used generally complexed methods based on sandwich-type bioassay however our biosensor is based on direct method of detection. It is of paramount importance to mention that this work is the first to use aptamer for PSA detection by the SERS technique.

\section{Table 1}

\subsection{Performance of the biosensor}

Selectivity and specificity are two very important characteristics that define a given aptasensing performance and validity. These two characteristics were evaluated in the presence of human serum albumin (HSA) and bovine serum albumin (BSA) as competing proteins to PSA. The selectivity and specificity tests were performed in the same conditions of PSA detection by adding $10 \mu \mathrm{g} . \mathrm{L}^{-1}$ of each interferent.

As it can be seen in Fig. 4A and Fig. 1S an excellent discrimination was observed in the SERS spectra intensity at $1550 \mathrm{~cm}^{-1}$ in presence of $10 \mu \mathrm{g} . \mathrm{L}^{-1}$ of the different proteins PSA, HSA and BSA, respectively. PSA gave a clear increase in SERS intensity at $1550 \mathrm{~cm}^{-1}$, which corresponds to amide II, but the other two proteins HSA and BSA do not cause any significant change in the SERS spectra of the biosensor, indicating a very good selectivity towards PSA. In addition, to illustrate the specificity, the aptasensor was tested by measuring and comparing the response of the two as-mentioned proteins in presence and in absence of PSA. No significant change in the SERS spectra of the proteins was observed without PSA, compared to 
those with PSA as it can be shown in Fig. 4A and Fig. 1S, indicating good specificity of the developed biosensing system.

The storage stability of the aptasensor was checked for a period of two months. The anti$\mathrm{PSA} / \mathrm{MCH} / \mathrm{AgNPs} / \mathrm{SiNWs}$ was kept in refrigerator at $4^{\circ} \mathrm{C}$. The SERS responses provided by the aptasensors with and whithout PSA were recorded each control day. Fig. 4B and Fig. 2S show that the designed biosensor exhibits a stable signal either in absence or in the presence of $5 \mu \mathrm{g} . \mathrm{L}^{-1}$ of PSA after 62 days of storage.

\section{Figure 4}

\subsection{Applicability in complex matrix}

Since this aptasensor has shown good selectivity against the proteins HSA and BSA existing in human blood serum, the selectivity of this device has also been tested in more complex samples (female blood serum purchased from Sigma-Aldich). It is worth noting that the levels of PSA in female serum blood is lower than $0.1 \mu \mathrm{g} . \mathrm{L}^{-1}$ [55], so it should not interfere in our assay since it below the limit of detection of the biosensor. In this context, two concentrations of PSA, $3 \mu \mathrm{g} . \mathrm{L}^{-1}$ and $6 \mu \mathrm{g} . \mathrm{L}^{-1}$, were added to the serum, which was diluted three times in PBS to reduce its viscosity. The detection process is the same as for a buffer solution. The Fig. 3S. displays the response SERS of the aptasensor before and after the addition of serum, $3 \mu \mathrm{g} . \mathrm{L}^{-1}$ and $6 \mu \mathrm{g} . \mathrm{L}^{-1}$ of PSA. This figure shows that the vibration modes of amide II at $1550 \mathrm{~cm}^{-1}$ appears after the addition of PSA and their intensities increase with increasing PSA concentrations. The analytical results are gathered in Table 2. The detected values of the PSA concentrations after serum spiking $(\mathrm{F})$ are close to those added ones $(\mathrm{P})$. The recovery values, presented in Table 2, are about 102 and 103\% for two samples (1 and 2). These figures show that the method can be reasonably applied for physiological fluids.

\section{Table 2}

\section{Conclusion}

We reported in the design of new bioplatform using aptamer tethered to AgNPs/SiNWs SERS substrate to detect selectively with specificity PSA form using an optic technique. The design stepwise procedure is simple yet giving high performance results. The detection of PSA was monitored by the apparition of amide vibration modes and the increasing of their intensities is timely dependant of the PSA concentrations in solution. The developed aptasensor is able to detect PSA in wide linear range of concentrations from 0.1 to $20 \mu \mathrm{g} . \mathrm{L}^{-1}$ in spiked PBS solutions. Finally, we validated in human serum samples as complex matrix and it shows very 
satisfactory results despite the complexity of human fluids. The amenable procedure can generalized to other proteins/aptamers or small molecules/aptamers using SERS or other optical techniques.

\section{Acknowledgments}

A.O. thanks the support from the University of Tunis El Manar for the mobility grant (Bourse d'alternance). Raman and EDX-SEM analysis were performedin the CCLO-Renatech clean room facilties of Institut Foton.

Authors thank the PHC-Maghreb (project ref.: 07MAG21) program for financial support. NR acknowledges the Tunisian Federated Research Program (PRF) the funding granted to NanoFastResponse (ref.: PRF2017-D4P1), SmartBioSens (ref.: PRFCOV19-D2P2) and COVID-PP (ref.: PRFCOV19-D3P1) projects.

\section{References}

[1] M. Arnold, H.E. Karim-Kos, Recent trends in incidence of five common cancers in 26 European countries since 1988: Analysis of the European Cancer Observatory, EJC 51 (2015) 1164-1187.

[2] C.O. Madu , Y. Lu, Novel diagnostic biomarkers for prostate cancer, J. Cancer 1 (2010) 150-177.

[3] P.F. Pinsky, P.C. Prorok, K. Yu, B.S. Kramer, A. Black, J.K. Gohagan, E.D. Crawford, R.L. Grubb, G.L. Andriole, Extended mortality results for prostate cancer screening in the PLCO trial with median follow-up of 15 years, Cancer 123 (2017) 592-599.

[4] R.A. Smith, C.J. Mettlin, H. Eyre, Cancer Medicine: Cancer Screening and Early Detection. In: Kufe DW, et al, editors. Cancer Medicine. Hamilton, Canada: BC Decker Inc. 2003.

[5] T.T.N. Do, T.V. Phi , T.P. Nguy, P.Wagner, K. Eersels, M.C. Vestergaard, L.T.N. Truong, Anisotropic In Situ-Coated AuNPs on Screen-Printed Carbon Surface for Enhanced Prostate-Specific Antigen Impedimetric Aptasensor, Journal of Elec. Materi. 46 (2017) 3542-3552.

[6] B. Acevedo, Y. Perera, M. Ruizb, G. Rojas, J. Benitez, M. Ayalaa, J. Gavilondo, Development and validation of a quantitative ELISA for the measurement of PSA concentration, Clin. Chim. Acta 317 (2002) 55-63.

[7] R.C. Zangar, D.S. Daly, A.M. White, ELISA microarray technology as a highthroughput system for cancer biomarker validation. Expert Rev. Proteomic. 3 (2006) 3744. 
[8] W. Chen, W. Jie, Z. Chen, X. Jie, J. Huang-Xian. Chemiluminescence immunoassay, Trends Anal. Chem. 28 (2009) 404-415.

[9] H. Li, Q. Wei, J. He, T, Li, Y. Zhao, Y. Cai, B. Du, Z. Qian, M. Yang, Electrochemical immunosensors for cancer biomarker with signal amplification based on ferrocene functionalized iron oxide nanoparticles. Biosens. Bioelectron. 26 (2011) 35903595.

[10] H.C.B. Graves, N. Wehner, T.A. Stamey, Ultrasensitive Radioimmunoassay of Prostate Specific antigen. Clin. Chem. 38 (1992) 735-742.

[11] S. Albrecht, H. Brandl, M. Steinke, T. Freidt, Chemiluminescent enzyme immunoassay of prostate specific antigen based on indoxyl phosphate substrate. Clin. Chem. 40 (1994) 1970-1971.

[12] Y. Wang, J. Irudayaraj, A SERS DNAzyme biosensor for lead ion detection. Chem. Commun.47 ( 2011) 4394-4396.

[13] Y. Pang , N. Wan, L. Shi , C. Wang, Z. Sun, R. Xiao, S. Wang, Dual-recognition surface-enhanced Raman scattering(SERS)biosensor for pathogenic bacteria detection by using vancomycin-SERS tags and aptamer-Fe3O4@Au. Anal. Chim. Acta 1077 (2019) 288-296.

[14] F. Wang, S. Cao, R. Yan, Z. Wang, D. Wang, H. Yang, Selectivity/Specificity Improvement Strategies in Surface-Enhanced Raman Spectroscopy Analysis, Sensors 17 (2017) 2689-2715.

[15] Y. Xu, F.Y.H. Kutsanedzie, M.M. Hassan, J. Zhu, W. Ahmad, H. Li, Q. Chen, Mesoporous Silica Supported Orderly-spaced Gold Nanoparticles SERS-based Sensor for Pesticides Detection in Food, food Chem. 315 (2020) 126300.

[16] J.T. Ryman , B. Meibohm, Pharmacokinetics of Monoclonal Antibodies, CPT Pharmacometrics Syst. Pharmacol. 6 (2017) 576-588.

[17] S.Knutson, E. Raja, R. Bomgarden, M. Nlend, A. Chen, R. Kalyanasundaram,S. Desai, Development and Evaluation of a Fluorescent Antibody-Drug Conjugate for Molecular Imaging and Targeted Therapy of Pancreatic Cancer. PLOS ONE, 11 (2016) 1-25. [18] Z. Zhuo, Y. Yu, M. Wang, J. Li, Z. Zhang, J. Liu, X. Wu , A. Lu, G. Zhang, B. Zhang, Recent Advances in SELEX Technology and Aptamer Applications in Biomedicine. Int. J. Mol. Sci. 18 (2017) 2142-2161.

[19] X. Wang, H.J. Lim, A. Son, Characterization of denaturation and renaturation of DNA for DNA hybridization. Environ. Health Toxicol. 29 (2014) 1-8. 
[20] W. Argoubi, A. Sánchez, C. Parrado, N. Raouafi, R. Villalonga, Label-free electrochemical aptasensing platform based on mesoporous silica thin film for the detection of prostate specific antigen, Sens. Actuators B Chem. 255 (2017) 309-315.

[21] M. Srivastava, N.R. Nirala, S.K. Srivastava, R. Prakash, A comparative Study of Aptasensor Vs Immunosensor for Label-Free PSA Cancer Detection on GQDsAuNRs Modified Screen-Printed Electrodes, Sci. Rep. 8 (2018) 1923-1934.

[22] T. Hao, X. Wu, L. Xu, L. Liu, W. Ma, H. Kuang, C. Xu, Ultrasensitive Detection of Prostate-Specific Antigen and Thrombin Based on Gold-Upconversion Nanoparticle Assembled Pyramids, Small 13 (2017) 1603944.

[23] X. Ma, X. Xu, Y. Xia, Z. Wang, SERS aptasensor for Salmonella typhimurium detection based on spiny gold nanoparticles, Food Control 84 (2018) 232-237.

[24] S. Li, W. Ma, X. Chen, K. Xie, Y. Li, X. He, X. yang, Y. Lei, Structure and Antireflection Properties of SiNWs Arrays Form mc-Si Wafer Through Ag-Catalyzed Chemical Etching, Appl. Surf. Sci. 369 (2016) 232-240.

[25] J. Wang, W. Lin, E. Cao, X. Xu, W. Liang, X. Zhang, Surface Plasmon Resonance Sensors on Raman and Fluorescence Spectroscopy, Sensors 17 (2017) 2719-2738.

[26] A. Ouhibi, M. Saadaoui, N. Lorrain, M. Guendouz, N. Raouafi, A. Moadhen, Application of Doehlert Matrix for an Optimized Preparation of a Surface-Enhanced Raman Spectroscopy (SERS) Substrate Based on Silicon Nanowires for Ultrasensitive Detection of Rhodamine 6G. Appl. Spectrosc 74 (2019) 168-177.

[27] M-L. Zhang, K-Q. Peng, X. Fan, J-S. Jie, R-Q. Zhang, et al., Preparation of LargeArea Uniform Silicon Nanowires Arrays Through Metal-Assisted Chemical Etching, J. Phys. Chem. 112 (2008) 4444-4450.

[28] S. Amdouni, Y. Coffinier, S. Szunerits, M.A. Zaïbi, M. Oueslati, R. Boukherroub, Catalytic activity of silicon nanowires decorated with silver and copper nanoparticles, Semicond. Sci. Technol. 31 (2016) 14011-14019.

[29] L. Li, M. Li, W. Wang, Q. Zhang, D. Liu, X. Li , H, Jiang, High Sensitivity Determination of TNF- $\alpha$ for Early Diagnosis of Neonatal Infections with a Novel and Reusable Electrochemical Sensor, Sensors 17 ( 2017) 992-1003.

[30] J.N. Murphy, A.K.H. Cheng, H-Z. Yu, D. Bizzotto, On the Nature of DNA SelfAssembled Monolayers on Au: Measuring Surface Heterogeneity with Elec trochemical in Situ Fluorescence Microscopy, J. AM. CHEM. SOC. 131 (2009) 4042-4050.

[31] E.A. Josephs, T. Ye, Nanoscale Spatial Distribution of Thiolated DNA on Model Nucleic Acid Sensor Surfaces, ACS NANO, 7 (2013) 3653-3660. 
[32] Z. Li, J. Yin, C. Gao, G. Qiu, A. Meng, Q. Li, The construction of electrochemical aptasensor based on coral-like polyaniline and Au nano-particles for the sensitive detection of prostate specific antigen, Sensor. Actuators B chem. 295 (2019) 93-100.

[33] J. M. Ashraf, M.A. Ansari, H. M. Khan, M.A.Alzohairy, I. Choi, Green synthesis of silver nanoparticles and characterization of their inhibitory effects on AGEs formation using biophysical techniques, Scientific Reports 6 (2016) 20414.

[34] G. Sharma, J-S. Nam, A. R. Sharma, S-S Lee. Antimicrobial Potential of Silver Nanoparticles Synthesized Using Medicinal Herb Coptidis rhizome, molecules, 23 (2018) 22682280.

[35] S. Amdouni, Y. Coffinier, S. Szunerits, M. Zaïbi , M. Oueslati, R. Boukherroub, Catalytic activity of silicon nanowires decorated with silver and copper nanoparticles, Semicond. Sci. Technol. 31 (2016) 014011 (8pp)

[36] J. Yin, X. Qi, L. Yang, G. Hao, J. Li, J. Zhong, A hydrogen peroxide electrochemical sensor based on silver nanoparticles decorated silicon nanowire arrays, Electrochim. Acta 56 (2011) 3884-3889.

[37] M. Rycenga, J.M. McLellan, Y. Xia, A SERS study of the molecular structure of alkanethiol monolayers on $\mathrm{Ag}$ nanocubes in the presence of aqueous glucose, Chem. Phys. Lett. 463 (2008) 166-171.

[38] E.E. Lawson, H.G.M. Edwards, A.F. Johnson, FT Raman spectroscopic study of the wavenumber region 2800-2630 cm of selected organic compounds, Spectrochim Actaa. 51 (1995) 2057-2066.

[39] N.B. Colthup, S.E. Wilberley, L.H. Daly, Introduction to Infrared and Raman Spectroscopy, Academic Press, 1964.

[40] K. Sun, Q. Huang, G. Meng, Y. Lu, Highly Sensitive and Selective SERS Label-free Detection of PCB-77 using DNA Aptamer Modified Ag-nanorod Arrays, ACS Appl. Mater. Interfaces 8 (2016) 8-31.

[41] Y. Lu, Q. Huang, G. Meng, L. Wu, Z. Jingjing, Label-free selective SERS detection of PCB-77 based on DNA aptamer modified SiO2@Au core/shell nanoparticles, Analyst 139 (2014) $3083-3087$.

[42] C.V. Pagba, S.M. Lanea, S.W. Hogiu, Raman and surface-enhanced Raman spectroscopic studies of the15-mer DNA thrombin-binding aptamer, J. Raman Spectrosc. 41 (2010) 241-247.

[43] S. He, H. Li, C.L. Gomes, D.V. Voronine, Tip-enhanced Raman scattering of DNA aptamers for Listeria monocytogenes, Biointerphases 13 (2018) 12p. 
[44] J. Bandekar, S. Krimmt, Vibrational analysis of peptides, polypeptides, and proteins: Characteristic amide bands of turns, Proc. Natl. Acad. Sci. 76 (1979) 774-777.

[45] Z. Chi, X.G. Chen, J.S. W. Holtz, S.A. Asher, UV Resonance Raman-Selective Amide Vibrational Enhancement: Quantitative Methodology for Determining Protein Secondary Structure, Biochemistry 37 (1998) 2854-2864.

[46] Z-Q. WEN, Raman Spectroscopy of Protein Pharmaceuticals, J. Pharm. Sci. 96 (2007) 2861-2878.

[47] A. Raouafi, A. Sánchez, N. Raouafi, R. Villalonga, Electrochemical aptamer-based bioplatform for ultrasensitive detection of prostate specific antigen, Sensor Actuat B-Chem. 297 (2019) 126762.

[48] L. Abbasya, A. Mohammadzadehd, M. Hasanzadeh, N. Razmi, Development of a reliable bioanalytical method based on prostate specific antigen trapping on the cavity of molecular imprinted polymer towards sensing of PSA using binding affinity of PSA-MIP receptor: A novel biosensor, Analysis 1885 (2020) 113447.

[49] F. Meng, H. Sun, Y. Huang, Y. Tang, Q. Chen, P. Miao, Peptide cleavage-based electrochemical biosensor coupling graphene oxide and silver nanoparticles, Anal. Chim. acta 24 (2019) 45-51.

[50] P. Jolly1, V. Tamboli, R.L. Harniman, P. Estrela, C.J. Allender, J.L. Bowen, AptamerMIP hybrid receptor for highly sensitive electrochemical detection of prostate specific antigen, biosens bioelectron. 75 (2016) 188-195.

[51] C. Fang, C. Chou, Y. Yang, T. Wei-Kai, Y. Wang, Y. Chan, Multiplexed Detection of Tumor Markers with Multicolor Polymer Dot-Based Immunochromatography Test Strip, Anal. Biochem. 90 (2018) 2134-2140.

[52] H. Chang, H. Kang, E. Ko, B-H. Jun, H-Y. Lee, Y-S. Lee, D.H. Jeong, PSA Detection with Femtomolar Sensitivity and a Broad Dynamic Range Using SERS Nanoprobes and an Area-Scanning Method, ACS Sens. 6 (2016) 645-649.

[53] D.S. Grubisha, R.J. Lipert, H-Y. Park, J. Driskell, M.D. Porter, Femtomolar Detection of Prostate-Specific Antigen: An Immunoassay Based on Surface-Enhanced Raman Scattering and Immunogold Labels, Anal. Chem., 75 (2003) 5936-5943.

[54] L. Yang, S. Zhen, Y. Lib, C. Huang, Silver Nanoparticles Deposited Graphene Oxide for Ultrasensitive Surface-Enhanced Raman Scattering Immunoassay of Cancer Biomarker, Nanoscale 1 (2013) 7p. 
[55] D. N. Melegos, H.Yu, M. Ashok, C. Wang, F. Stanczyk, E. P. Diamandis, ProstateSpecific Antigen in Female Serum, a Potential New Marker of Androgen Excess, J. Clin. Endocrinol. Metab. 82 (1997) 777-780. 


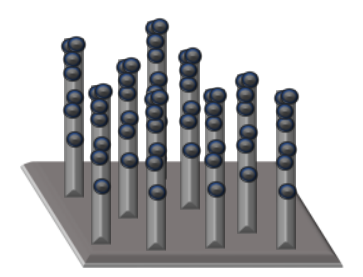

AgNPs/SiNWs

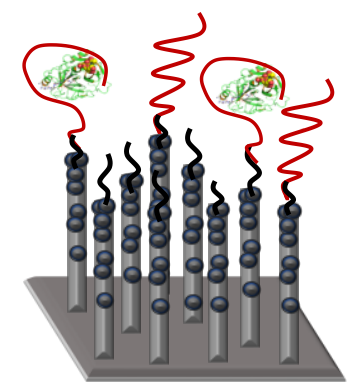

$\mathrm{MCH}$

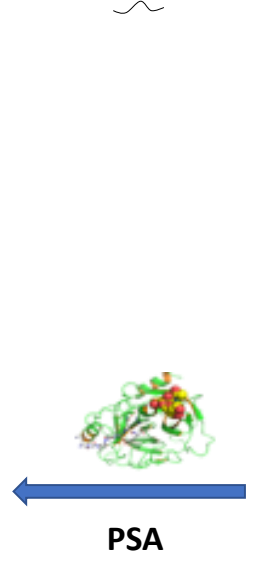

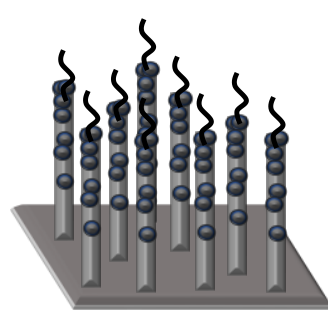

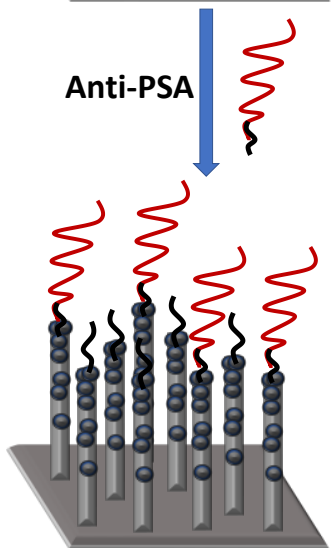

Figure 1. Schematic representation of the strategy of the stepwise assembly of the bioplatform and operation. 

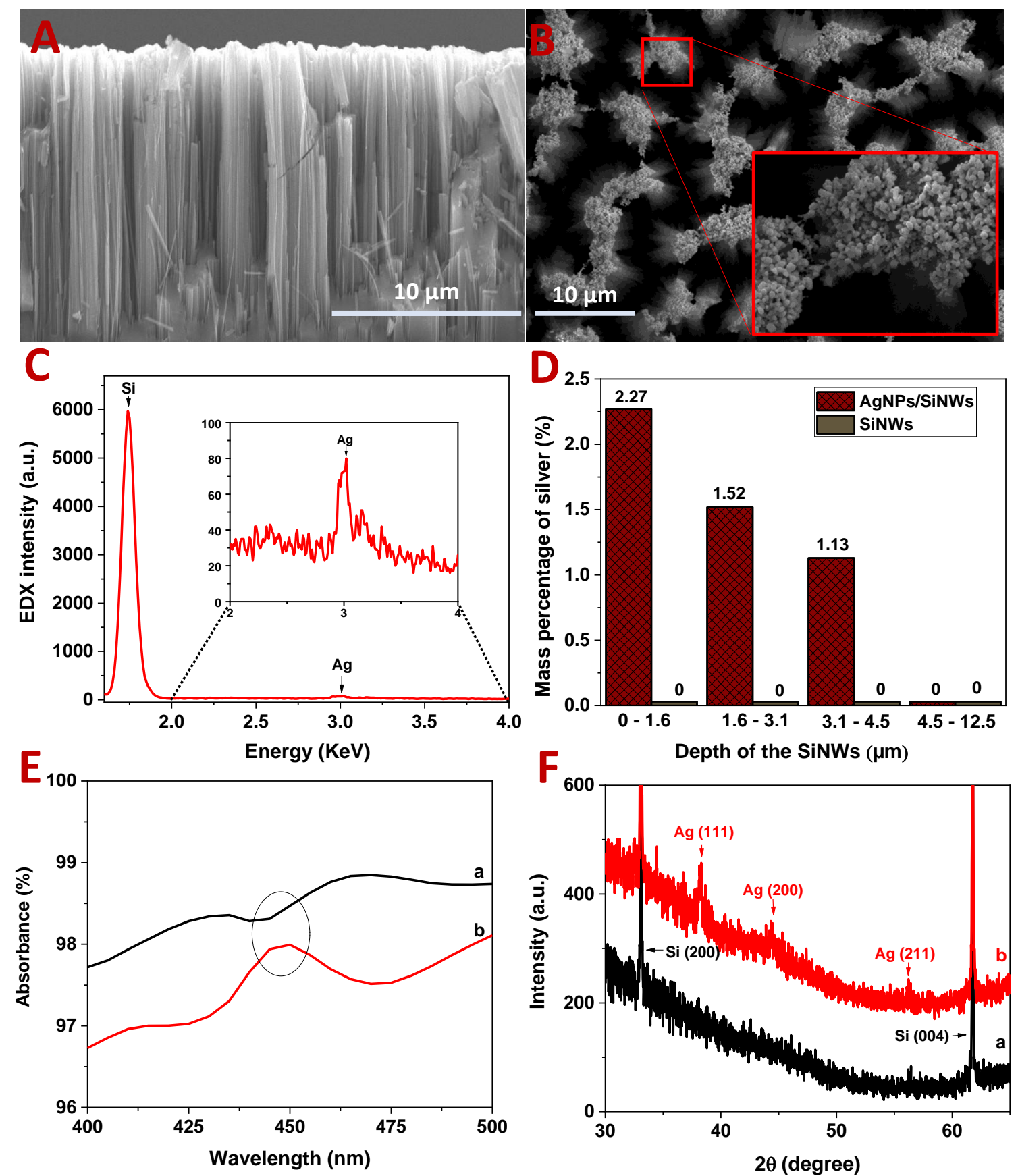

Figure 2. (A) SEM cross-section image of SiNWs, (B) SEM top surface view of AgNPs/SiNWs, (C) EDX spectrum of AgNPs/SiNWs from the surface until $1.6 \mu \mathrm{m}$, (D) Mass percentage of silver for SiNWs in deph before and after AgNPs decoration, (E) UV-visible absorbance spectra and (F) XRD patterns and of SiNWs (a) and AgNPs/SiNWs (b). 

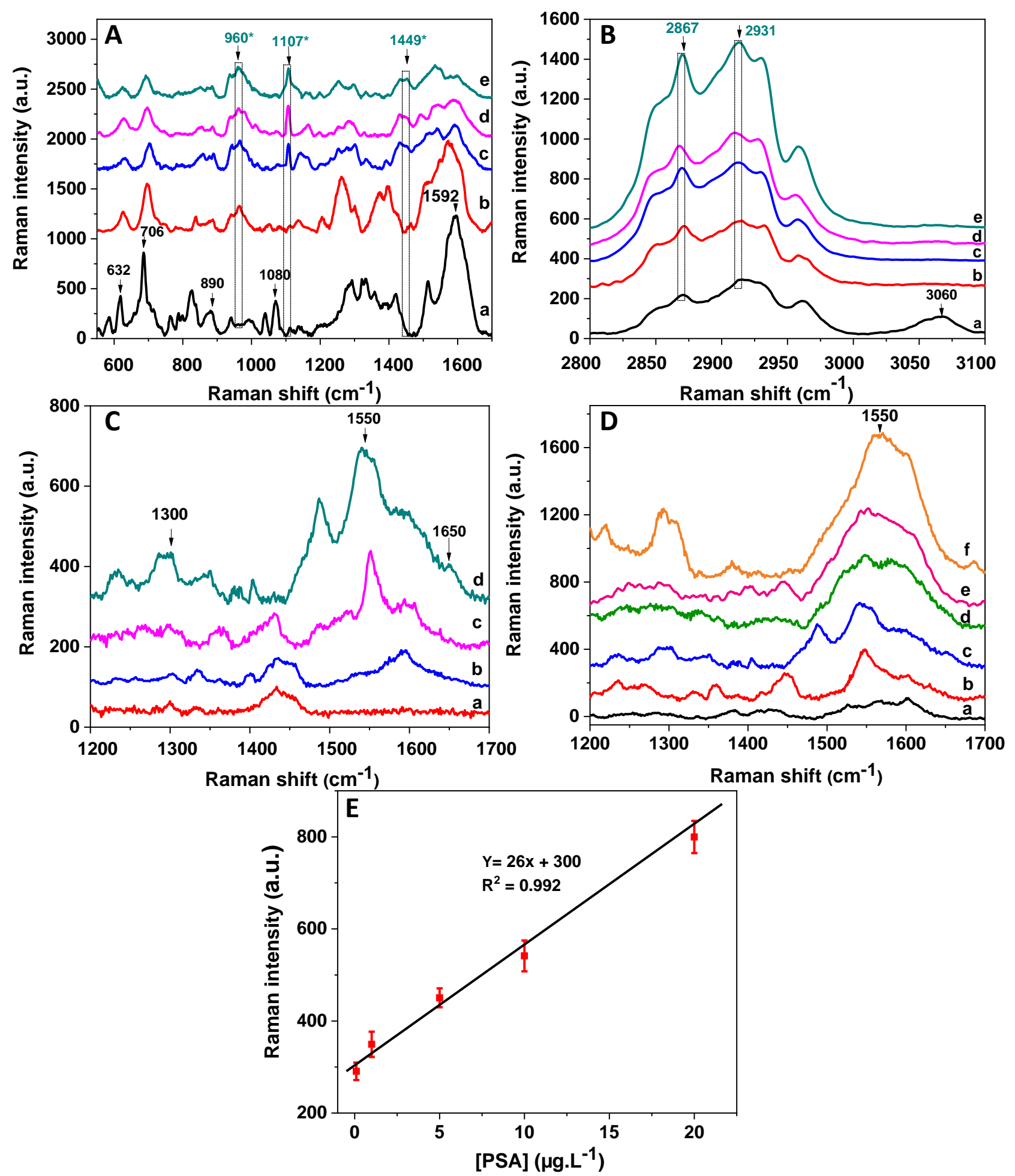

Figure 3. Raman spectra of MCH/AgNPs/SiNWs (a) and antiPSA/MCH/AgNPs/SiNWs for different incubation times in aptamer ; $4 \mathrm{~h}$ (b), $8 \mathrm{~h}$ (c), 12h (d) and 16h (e) for two frequency ranges: 550-1700 $\mathrm{cm}^{-1}$ (A) and 2800-3100 $\mathrm{cm}^{-1}$ (B). Raman spectra of PSA $\left(1 \mu \mathrm{g} . \mathrm{L}^{-1}\right) /$ anti-PSA/MCH/AgNPs/SiNWs for different incubation times ; $4 \mathrm{~h}$ (a), $8 \mathrm{~h}$ (b), $12 \mathrm{~h}$ (c) and 16h (d) of the SERS substrate 
(MCH/AgNPs/SiNWs) in aptamer solutions (C). SERS spectra of aptasensing system anti-PSA/AgNPs/SiNWs before (a) and after incubation in different PSA solutions with gradually increasing concentrations; $0.1 \mu \mathrm{g} . \mathrm{L}^{-1}$ (b), $1 \mu \mathrm{g} . \mathrm{L}^{-1}$ (c), $5 \mu \mathrm{g} . \mathrm{L}^{-1}$ (d), 10 $\mu \mathrm{g} . \mathrm{L}^{-1}$ (e) and $20 \mu \mathrm{g} . \mathrm{L}^{-1}$ (f) (D). Calibration curve of the developed aptasensor for PSA detection $(\mathbf{E})$.
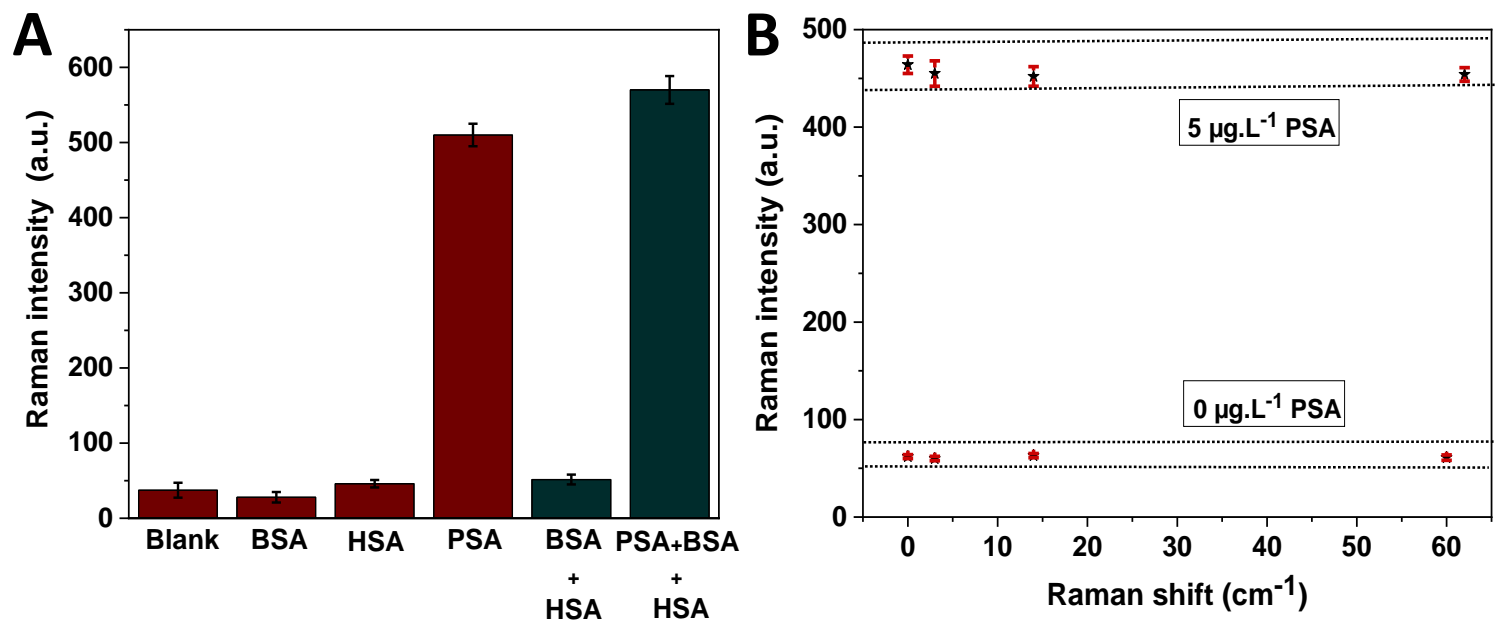

Figure 4. Analytical response of the aptasensor toward different proteins: PSA (10 $\left.\mu \mathrm{g} . \mathrm{L}^{-1}\right)$, BSA $\left(10 \mu \mathrm{g} . \mathrm{L}^{-1}\right)$ and HSA $\left(10 \mu \mathrm{g} . \mathrm{L}^{-1}\right)$ (A). Storage stability of the aptasensor stored for 62 days at $4{ }^{\circ} \mathrm{C}$ and its response in presence of $5 \mu \mathrm{g} \cdot \mathrm{L}^{-1}$ of PSA recorded perdiocally (B).

Table 1 : Comparison of the performances of some reported biosensors using electrochemical and optical technique with the present work.

\begin{tabular}{|l|l|l|l|l|l|l|}
\hline Detection system & Method & $\begin{array}{l}\text { Range of } \\
\text { variation } \\
\left(\boldsymbol{\mu g . \mathbf { L } ^ { - 1 }}\right)\end{array}$ & $\begin{array}{l}\text { LOD } \\
\left(\boldsymbol{\mu} \text { g. } \mathbf{L}^{-\mathbf{1}}\right)\end{array}$ & $\begin{array}{l}\text { Storage } \\
\text { stability }\end{array}$ & Selectivity & Ref. (Year) \\
\hline $\begin{array}{l}\text { SPCE/GO- } \\
\mathrm{CO}_{2} \mathrm{H} / \mathrm{apta} / \mathrm{cDNA} \\
/ \mathrm{MB}\end{array}$ & DPV & $0.001-100$ & $\begin{array}{l}0.064 \times 1 \\
0^{-3}\end{array}$ & $\begin{array}{l}\text { Two } \\
\text { weeks }\end{array}$ & $\begin{array}{l}\text { IgG, CEA and } \\
\text { HSA }\end{array}$ & $47(2019)$ \\
\hline $\begin{array}{l}\text { MIP/PTBs/Au } \\
\text { elecrode }\end{array}$ & DPV & $1-60$ & --- & 14 days & CEA and HSA & $48(2020)$ \\
\hline Apt/MSF/Au & DPV & $1-300$ & 0.28 & 30 days & BSA, HIgG & $20(2017)$ \\
\hline $\begin{array}{l}\text { GO-AgNPs } \\
\text { nanocomposite }\end{array}$ & LSV & $\begin{array}{l}5 \times 10^{-3}-20 \times \\
10^{-3}\end{array}$ & $\begin{array}{l}0.33 \times \\
10^{-3}\end{array}$ & ---- & $\begin{array}{l}\text { CEA, AFP and } \\
\text { BSA }\end{array}$ & $49(2019)$ \\
\hline
\end{tabular}




\begin{tabular}{|l|l|l|l|l|l|l|}
\hline Au/apta-MIP & $\begin{array}{l}\text { Capaci- } \\
\text { tance }\end{array}$ & $0.1-100$ & 0.001 & ---- & HK2 and HSA & 50 (2016) \\
\hline $\begin{array}{l}\text { GCE/PANI/Au/Pe } \\
\text { ptide }\end{array}$ & DPV & $0.0001-100$ & 0.085 & 7 days & CEA, IgG and HSA & $32(2019)$ \\
\hline $\begin{array}{l}\text { PS/PEG/COOH- } \\
\text { PDOT }\end{array}$ & $\begin{array}{l}\text { Fluores- } \\
\text { cence }\end{array}$ & $3-15$ & 2.05 & --- & CEA and AFP & $51(2018)$ \\
\hline $\begin{array}{l}\text { SERS } \\
\text { dots/Ab } / \text { /PSA/Ab2 } \\
\text { /SERS dots }\end{array}$ & SERS & $0.001-1000$ & $0.11 \times 10^{-}$ & --- & ---- & $52(2016)$ \\
\hline $\begin{array}{l}\text { Glass/Au/A } / \text { PSA/ } \\
\text { Ab } / \text { Au-reporter }\end{array}$ & SERS & $0.001-1000$ & $4 \times 10^{-3}$ & --- & ---- & $53(2003)$ \\
\hline $\begin{array}{l}\text { GO-AgNPs } \\
\text { Raman } \\
\text { spectros- } \\
\text { copy }\end{array}$ & $0.0005-0.5$ & 0.23 & ---- & $\begin{array}{l}\text { AFP, CEA, GSH, } \\
\text { Lys, Ala, ALP, }\end{array}$ & $54(2018)$ \\
\hline $\begin{array}{l}\text { anti-PSA/MCH/ } \\
\text { AgNPs/SiNWs }\end{array}$ & $\begin{array}{l}\text { Raman } \\
\text { spectros- } \\
\text { copy }\end{array}$ & $0.1-20$ & 0.1 & $\begin{array}{l}\text { Two } \\
\text { months }\end{array}$ & BSA and HSA & $\begin{array}{l}\text { This work } \\
(2020)\end{array}$ \\
\hline
\end{tabular}

SPCE: Screen-printed carbon electrodes, GO: graphene oxide, apta: anti-PSA aptamer, MB: methylene blue, DPV: differential pulse voltammetry, IgG: Immunoglobulin G, CEA: Carcino Embryonic Antigen, HSA: Human serum albumin, PTBs: poly[Toluidine blue], Au: gold electrode, MSF: Mesoporous silica thin films, BSA : Bovine serum albumin, AFP: Human alpha fetoprotein, HK2: Human glandular Kallikrein 2, MIP: molecularly imprinted polymer, GCE: glass carbon electrode, PANI: poly-aniline, PS-PEG-COOH: Polystyrene graft ethylene oxide, PDOT: polymer dots, AgNPs : silver nanoparticules, GSH: glutathione, Lys: lysine, Ala; alanine, ALP: alkaline phosphatase, GLB; globulin., Ab: antibody, LSV : linear sweep voltammetry.

Table 2 : Determination of PSA in spiked human blood serum

\begin{tabular}{|c|c|c|c|c|c|}
\hline Samples & Serum $(\mathbf{R})$ & $\begin{array}{c}\text { Added (P) } \\
\left(\mu \mathrm{g} . \mathrm{L}^{-1}\right)\end{array}$ & $\begin{array}{r}\text { Found (F) } \\
\left(\mu \mathrm{g} . \mathrm{L}^{-1}\right)\end{array}$ & $\operatorname{RSD}^{2}(\%)$ & $\begin{array}{l}\text { Recovery }^{3} \\
(\%)\end{array}$ \\
\hline 1 & $\mathrm{ND}^{1}$ & 3 & 3.07 & 5.0 & $97.7 \pm 5$ \\
\hline 2 & $\mathrm{ND}^{1}$ & 6 & 6.17 & 10.01 & $97.2 \pm 10$ \\
\hline
\end{tabular}

${ }^{1} \mathrm{ND}$ : not detected, ${ }^{2}$ Relative standard deviation (RSD) of 3 measurements, ${ }^{3}$ Recovery $(\%)=100 \times[\mathrm{R}+\mathrm{P}] /[\mathrm{F}]$. 